\title{
Observations on cortical blindness and on vascular lesions that cause loss of recent memory
}

\author{
G. S. BRINDLEY AND I. JANOTA \\ From the Departments of Physiology and Neuropathology, Institute of Psychiatry, London
}

SYNOPSIS Two long-surviving cases of cortical blindness are described, one total and the other total except for detection of sudden transitions from light to darkness and darkness to light. Both suffered from severe defect of recent memory, which lasted a month in one, and till death after nearly six years in the other. One patient survives. Necropsy findings on the other are given.

Monkeys deprived of all their striate cortex (area 17) and the neighbouring parts of areas 18 and 19 appear totally blind for the first few weeks, but later recover a wide range of visual functions (Klüver, 1942; Humphrey and Weiskrantz, 1967; Schilder et al., 1971). Part, at least, of this extrageniculostriate visual function persists after ablation of the temporal neocortex or of the superior colliculi (Pasik and Pasik, 1973a). The only lesions yet known to abolish it involve the accessory optic system (Pasik and Pasik, 1973b).

In man, on the other hand, total or very nearly total blindness from lesions that affect the occipital lobes and spare the optic nerves and tracts has been known to last five-and-a-half months (Monbrun and Gautrand, 1920) and probably two years five months (Saenger, 1919) in young adults, and as long as two years 10 months (Ter Braak et al., 1971) and even five years 11 months (the present paper) in elderly people.

Many who study the visual system would like to know whether this difference depends on the difference of species; or on the failure of the experimenters who removed the occipital lobes in monkeys to destroy all striate cortex; or on the involvement, in the human cases, of structures other than the striate cortex and geniculocalcarine tracts.

The main reason for publishing the clinical and pathological observations of the present paper is to help in resolving the above problem. The observations also make a small contribution (Accepted 7 January 1975.) to defining the range of lesions that cause loss of recent memory.

Two cases of cortical blindness will be described, both accompanied by loss of recent memory, which was transient in the first and permanent in the second.

The first patient came to see G.S.B. at the request of Professor R. W. Gilliatt on 30 April 1971. The observations quoted below about the first three months of her blindness come mainly from notes of the National Hospital, Queen Square. In May 1971 she returned to her home in Afghanistan. From there her husband wrote about her progress, and she was examined at the N.O.O.R. Eye Institute in Kabul in February 1974 by Mr J. D. C. Anderson, FRCS, whose observations complete the account.

The second is case 2 of Brindley et al. (1969). When she died, a necropsy was done in Exeter by Dr Sylvia Davies, who sent the brain to be examined in this Institute.

\section{CASE 1}

In January 1971, at age 47 years, this Afghan mother of many children, who had taken oral contraceptives for the past five years, suddenly developed severe headache and then lost consciousness. When she recovered consciousness an hour or so later she was blind, confused and disorientated, and had a right hemiparesis. For the next month she was unable to remember new things for more than 10 minutes. She came to England and was admitted to the National Hospital in April 1971. By then she could remember 459 
blind. The fundi were normal. There were no abnormal cranial nerve signs except for the blindness; in particular, both pupils reacted well to light. There was a slight right hemiparesis. No dysphasia or dysarthria could be detected by non-Pushtu-speaking British neurologists (she knows no English). Gamma scan was normal. Arteriograms showed partial occlusion of the left posterior cerebral artery and irregularity of calibre of the right vertebral artery. Optokinetic nystagmus was absent.

When seen by G.S.B. on 30 April 1971 she was totally unable to detect the switching on of a very bright light in a previously dark room, or the switching off of that light, or to distinguish between the two directions of movement of a large optokinetic nystagmus drum surrounding her, though she was quick and accurate in all non-visual sensory tests, including the naming (her husband present to interpret) of objects placed in either hand.

In April 1972 her husband wrote from Kabul that she could distinguish light from darkness. In October 1973 he wrote that she could still do this, but that her sight had not improved further.

In February $1974 \mathrm{Mr}$ Anderson found that besides distinguishing light from darkness she could detect movements of large conspicuous objects in the left half of her visual field between the midline and about $30^{\circ}$ out, and in this part of the field could distinguish between vertical and horizontal movements. She could see nothing in the right half-field. There was no optokinetic nystagmus to slowly-moving black and white stripes each subtending $5^{\circ}$ at the eye, even though the patient could detect the movement. The pupils reacted to light. The fundi were normal. The right ankle jerk was brisker than the left, and the right plantar response equivocal. There was no dysphasia or dysarthria, and no astereognosis. She could remember well what she had done in the last few days and weeks, and was aware of current world news.

\section{CASE 2}

This widow, born about 1896 , had complete heart block with occasional Stokes-Adams attacks from 1962. In October 1966 she was found unconscious at home. After three weeks of slow improvement in her level of consciousness, it became clear that she was blind. In December 1966 she was unable to distinguish steady darkness from steady light or detect a light moved about in front of her, but she could consistently distinguish sudden darkening of a lighted room from sudden lightening of a dark room. The pupils reacted to light. Eye movements to command were normal. Optokinetic nystagmus and visual evoked potentials were absent. A brain scan with $\mathrm{Hg}$ chlormerodrin showed dense symmetrical occipital uptake. She was unable to remember any new thing for more than 45 seconds.

She remained in this state, with very little change, until 1969. The paper of Brindley et al. (1969) gives further clinical information up to this year. A detail not quoted there is that on 23 December $1966 \mathrm{Dr}$ S. P. Meadows noted that, though her optic discs were pale, the pallor was no more than might be accounted for by her slight myopia.

She was visited by G.S.B. five more times. Brief Stokes-Adams attacks were very frequent between January and July 1969 . Then none were seen until June 1972, when three were seen. She died suddenly on 23 October 1972, presumably from another Stokes-Adams attack. Up to the day of her death she remained able to make good trivial conversation, to put on clothes if they were handed to her, and to walk as well as the average blind person of her age. Notes of four visits follow:

31 OCTOBER 1969 Pulse 36/min and regular. Fundi are normal except for slight pallor of the discs. Pupils react well to light. She can, as usual, distinguish switching on from switching off the overhead light in an otherwise dark room, but fails to detect when an ophthalmoscope light is directed into one eye, or when it is moved up and down or from side to side.

26 MAY 1970 Pulse 33/min. Pupils and vision are as usual. Optokinetic nystagmus is totally absent, not only at the usual drum speed of about $20^{\circ} / \mathrm{s}$, but down to $6 \%$. She answers questions about things that happened to her in the years 1926 and 1945, and about her work (proof reader of street directories) with fair accuracy, as verified by her sister-in-law. She thinks the year is now 'about 1960', and does not know the month or where she is. She can repeat six digits forwards and five backwards, if she attends continuously to the task; but a sequence of four digits repeated to her and then by her 20 times is not remembered after a brief distraction has intervened.

25 NOVEMBER 1970 (In September 1970 she had been moved to a different nursing home.) Pupils react to light. Optokinetic nystagmus is still absent at drum speeds $20 \% \mathrm{~s}$ and $6 \%$ s. Vision was not tested (no dark room). She can write her name, draw a square, add shillings and pence quickly and accurately, and identify her own left hand and left eye correctly. She cannot read an embossed word ('FOOD') by touch, though she names each letter slowly but confidently, because the beginning of the word is forgotten before its end has been read. She scores between the 10th and the 25 th percentile on 
the Mill Hill vocabulary test. She remembered one striking and unusual event (my playing the flute to her) 20 minutes later. This is the only occasion since the beginning of her illness when she has undoubtedly remembered a new event for more than two minutes.

21 August 1971 Pulse 34/min. Pupils react to light. She cannot now distinguish switching a light on in a dark room from switching it off in a lit one. She has not, in nearly a year, learned the topography of her bedroom or the names of any of her attendants or fellow-patients.

She recognized promptly a tune played to her on the flute, but 10 minutes later did not remember the event, and when told of it could not say what tune had been played.

NECROPSY There were no notable abnormalities outside the heart, brain, and optic nerves. The eyes were not examined.

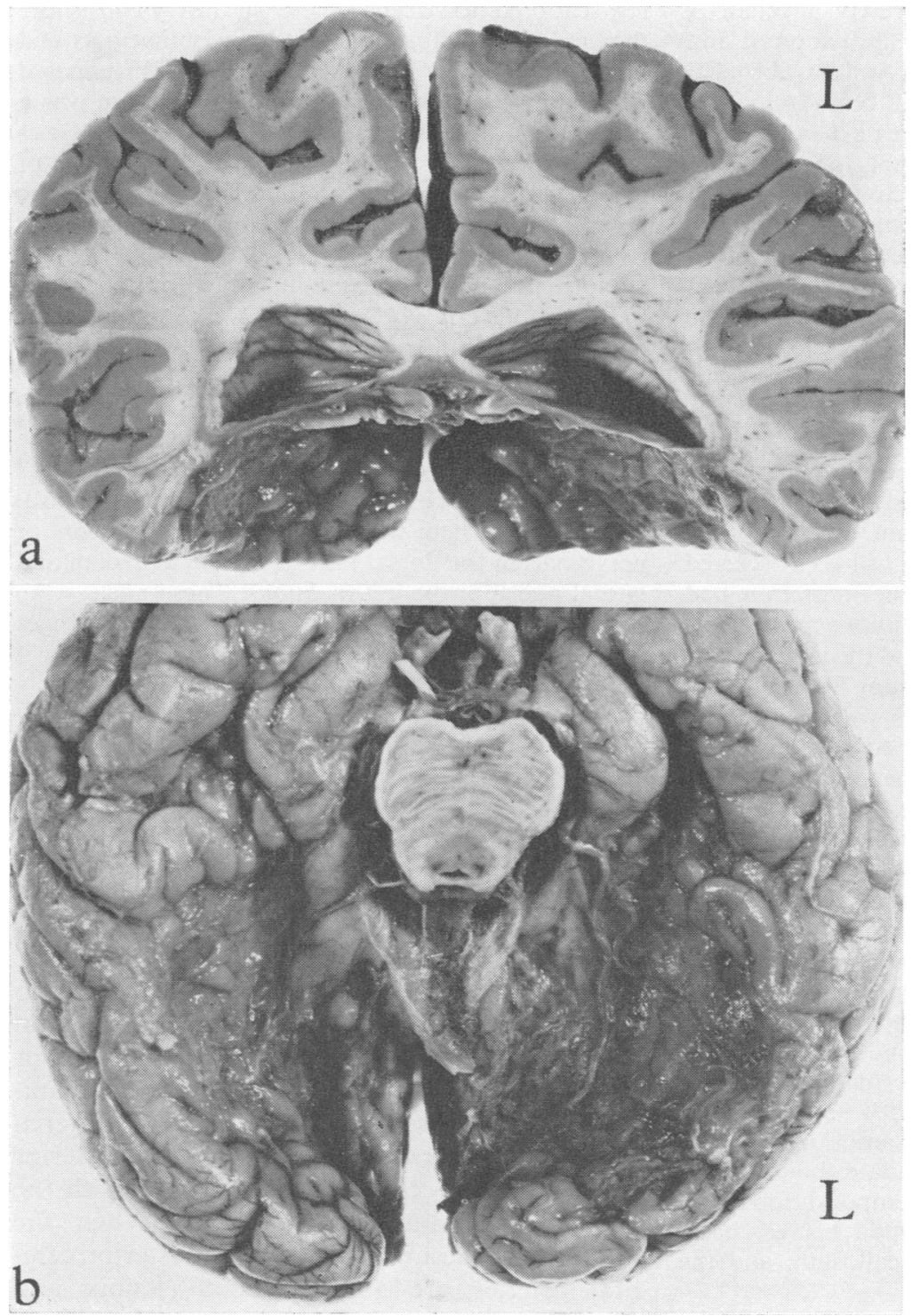

FIGURE (a) Coronal section showing destruction of the brain medial to the inferior temporal gyri and scarred remnants of the hippocampus just under the posterior end of the corpus callosum.

(b) Under aspect of the brain. There is extensive destruction of the temporal and occipital lobes. The uncus is preserved anterior to the lesion and some cortex is seen at the occipital poles. 
The heart (report of Dr R. C. Evans) weighed $402 \mathrm{~g}$. There was no gross external pathology. The coronary arteries showed only slight atheroma, and the arteries to the conducting system were all patent. The main bundle of His and bundle branches showed changes consistent with a diagnosis of idiopathic bundle branch fibrosis.

The brain weighed $1020 \mathrm{~g}$. All the arteries of the circle of Willis were atheromatous and the lumen of the posterior cerebral arteries beyond their junction with the posterior communicating arteries narrowed to a pinhole. Both optic nerves were grey, the right more so than the left. The optic tracts were softened and grey, the left being more severely affected. A large part of the under aspect of the temporal and occipital lobes was reduced to a yellow fibroglial membrane with shrunken gliosed brain remnants (Figure, $a$ and $b$ ). The infarcted area extended on to the medial surface of the occipital lobes; it was bordered above by the parieto-occipital fissure, but some cortex remained at the occipital poles on both sides. Anteriorly and medially the infarct involved the greater part of the hippocampus and the adjacent gyri on both sides; the uncus was preserved. The parahippocampal gyrus (also known as hippocampal gyrus) was shrunken on the left while its anterior part was recognizable on the right. The fusiform gyrus was destroyed on both sides, as were the lingual gyri, apart from their posterior part, and the cunei. Coronal slices showed that anteriorly there was destruction of the brain medial to the inferior temporal gyri including all but scarred remnants of the hippocampus. The infarction had completely destroyed the hippocampus posteriorly where it also involved the fornix and the inferior part of the splenium of the corpus callosum. The shrunken and grey lateral geniculate bodies were not in the infarcted area, which, however, completely interrupted their connections with the occipital lobes. Examination of the rest of the cerebral hemisphere showed a moderate dilatation of the lateral and third ventricle and a cystic lesion in the left globus pallidus and the anterior limb of the internal capsule. The lesion was surrounded by gliosis which involved the left thalamus posterior to it, where it was shrunken and brown, but the pulvinar appeared to be preserved. The aqueduct was dilated to $2.5 \mathrm{~mm}$ in diameter. The superior colliculi and the rest of the brainstem and cerebellum were normal.

Histological examination included serial sections of the optic tracts and hypothalamus and of the thalamus and the lateral geniculate bodies, and sections of hippocampus and temporal lobe and occipital lobe on both sides. Optic nerves, basal ganglia, splenium of the corpus callosum, and the midbrain were also examined.
The extent of the infarction of the occipital lobes with destruction of the geniculocalcarine connections were confirmed. The surviving cortex at the occipital poles might have been expected, by analogy with the published maps of visual cortex (Filimonoff, 1932; Polyak, 1957; Brindley, 1972), to include some striate area. In fact, there was too much cell loss and gliosis to allow any morphological classification. The lumen of both posterior cerebral arteries was much narrowed with fibrous tissues within normal internal elastic lamina and normal media suggestive of an organized thrombus or embolus.

The lateral geniculate bodies contained only a very few scattered nerve cells. There was heavy gliosis and the laminar structure was lost. The optic tracts and optic nerves showed gliosis and loss of myelinated nerve fibres. The left optic tract, where there was a diffuse loss of about two-thirds of nerve fibres, was more severely affected than the right one. The loss of nerve fibres was quite considerable in the optic nerves, but some fibres were present in all quadrants of both nerves.

Normal landmarks were just discernible in the hippocampus anteriorly, but the greater part of that structure on both sides was replaced by scar tissue. The fimbriae were shrunken and gliosed, as were the fornices throughout their course. Less than half of the nerve fibres in the fornices had remained. The number of nerve cells in the mammillary bodies was not greatly reduced, but there was gliosis in bothe these nuclei. There was severe gliosis with a loss of nerve cells in the dorsal part of the dorsomedian and lateral nuclei of the left thalamus. These nuclei were normal on the right side, and no definite changes were found in the anterior thalamic nuclei.

\section{DISCUSSION}

Few cases with severe disturbance of both memory and vision from an infarct have been published. These few would include case 3 of the 12 cases of bilateral loss of vision from cerebral infarction described by Symonds and MacKenzie (1957) and the one case of Ter Braak et al. (1971). In other recorded instances of lesions similar to those in our case 2 , the clinical emphasis is on the memory disturbance (DeJong et al., 1969) or blindness but not on both. The clinical manifestations are due to the infarction of the territories of the brain supplied by the posterior cerebral arteries beyond their junction with the posterior communicating arteries. When the basilar and the first parts of the posterior cerebral arteries are also occluded (Kubik and 
Adams, 1946), the effects of lesions in the brainstem, thalamus, and subthalamus will dominate the clinical presentation, as happened in the last phase of life of the case of Victor et al. (1961). Where the posterior communicating arteries are healthy, the effect of occlusion of the first parts of the posterior cerebral arteries and of the basilar arteries is confined to the brain-stem, subthalamus, and the inferior parts of the thalamus (for example, Segarra, 1970; Janota, unpublished), and the hippocampus and the occipital lobe are spared. Infarcts restricted to the hippocampus on the two sides (von Bechterew, 1900; Glees and Griffith, 1952) are rare, and vascular lesions confined to the occipital lobes are usually unilateral, associated with a compression of the posterior cerebral vessels by the edge of the tentorium.

CORTICAL BLINDNESS Case 1 shows that total cortical blindness can outlast the severe disorder of memory that initially accompanied it. The absence of any oculomotor disturbance makes it unlikely that there is any brainstem lesion, and therefore unlikely that the totality of her initial blindness can be attributed to a lesion of the accessory optic tracts. Her recovery, between three and 15 months after the onset of blindness, of some vision in the left half of the visual field presumably indicates that some part of her right geniculocortical system escaped destruction.

Case 2 is by a substantial margin the longestsurviving case of almost total cortical blindness yet reported. The tidiness of the case, as one of cortical blindness, is marred by the observation of loss of optic nerve fibres. The most likely cause of this loss is ischaemic damage to the retinas at the time of the Stokes-Adams attack that caused the main cortical lesion; but it could possibly be a retrograde trans-synaptic change due to the loss of lateral geniculate cells. Whatever its cause, it was diffuse and permitted a reaction of the pupils to light which (though it sometimes seemed a little sluggish and lacking in amplitude) was accepted by several neurologists on several occasions as within normal limits. There was no infarct in the upper brainstem, and therefore no ground for supposing that accessory optic fibres or fibres to the superior colliculi would be more than proportionately represented among those that were lost. The functional counterpart in man of the inferotemporal region of rhesus monkeys, lesions of which severely impair the performance of learned visual discriminations (Mishkin, 1954; see also Gross, 1973) is unknown, but if it is the apparent gross anatomical counterpart (inferior temporal gyrus), then it mainly escaped infarction.

LOSS OF RECENT MEMORY The memory disturbance found in our case 2 resembles that occurring after the destruction of the whole of the so-called limbic system or with lesions which interrupt the limbic connections. The limbic system is selectively affected in herpes simplex encephalitis, and there are instances of loss of recent memory in long-surviving patients (Friedman and Allen, 1969; Gascon and Gilles, 1973). A similar state occurs after bilateral temporal lobectomy (Scoville and Milner, 1957), sometimes but probably not always after section of the fornices (Sweet et al., 1959, but see also Whitty, 1962) and in Wernicke's encephalopathy. It is also encountered with bilateral infarctions of the medial temporal structures (Glees and Griffith, 1952; Victor et al., 1961; DeJong et al., 1969). The main features that our case 2 shares with the above patients are that memory within the span of attention is normal, that new material is never or hardly ever remembered beyond the span of attention, even after many repetitions, and that memory for events before the beginning of the disease is fairly well preserved.

We have been much helped by many people in collecting the information assembled here. Besides those named in the text, we should like to thank Professor P. M. Daniel of this Institute, Dr J. N. Blau of the National Hospital, Queen Square, and Mrs M. L. Austin, SRN, of the Clarondene Nursing Home, Lyme Regis.

\section{REFERENCES}

Bechterew, W. von (1900). Demonstration eines Gehirns mit Zerstörung der vorderen und innern Theile der Hirnrinde beider Schläfenlappen. (Abstract.) Neurologisches Centralblatt, 19, 990-991.

Braak, J. W. G. ter, Schenk, V. W. D., and Vliet, A. G. M. van (1971). Visual reactions in a case of long-lasting cortical blindness. Journal of Neurology, Neurosurgery, and Psychiatry, 34, 140-147.

Brindley, G. S. (1972). The variability of the human striate cortex. Journal of Physiology, 225, 1-3P.

Brindley, G. S., Gautier-Smith, P. C., and Lewin, W. (1969). Cortical blindness and the functions of the non-geniculate fibres of the optic tracts. Journal of Neurology, Neurosurgery, and Psychiatry, 32, 259-264. 
DeJong, R. N., Itabashi, H. H., and Olson, J. R. (1969). Memory loss due to hippocampal lesions. Report of a case. Archives of Neurology, 20, 339-348.

Filimonoff, I. N. (1932). UUber die Variabilität der Grosshirnrindenstruktur. 2: Regio occipitalis beim erwachsenen Menschen. Journal für Neurologie und Psychiatrie, Leipzig, 44, 2-96.

Friedman, H. M., and Allen, N. (1969). Chronic effects of complete limbic lobe destruction in man. Neurology (Minneap.), 19, 679-690.

Gascon, G. G., and Gilles, F. (1973). Limbic dementia. Journal of Neurology, Neurosurgery, and Psychiatry, 36, 421-430.

Glees, P., and Griffith, H. B. (1952). Bilateral destruction of the hippocampus (cornu ammonis) in a case of dementia. Monatsschrift für Psychiatrie und Neurologie, 123, 192-204.

Gross, C. G. (1973). Visual functions of inferotemporal cortex. Handbook of Sensory Physiology, vol. 7/3B, pp. 451-482. Edited by R. Jung. Springer: Berlin.

Humphrey, N. K., and Weiskrantz, L. (1967). Vision in monkeys after removal of the striate cortex. Nature, 215, 595-597.

Kluver, H. (1942). Functional significance of the geniculostriate system. Biological Symposia, 7, 253-299.

Kubik, C. S., and Adams, R. D. (1946). Occlusion of the basilar artery-a clinical and pathological study. Brain, 69, 73-121.

Mishkin, M. (1954). Visual discrimination performance following partial ablations of the temporal lobe: 2 . Ventral surface vs. hippocampus. Journal of Comparative Physiology and Psychology, 47, 187-193.

Monbrun, A., and Gautrand, G. (1920). Quatre observations d'hémianopsie double. Archives d'Ophtalmologie, 37, 232-238.

Pasik, T., and Pasik, P. (1973a). Extrageniculostriate vision in the monkey. 4. Critical structures for light $v s$. no-light discrimination. Brain Research, 56, 165-182.

Pasik, P., and Pasik, T. (1973b). Extrageniculostriate vision in the monkey. 5. Role of accessory optic system. Journal of Neurophysiology, 36, 450-457.

Polyak, S. (1957). The Vertebrate Visual System. University of Chicago Press: Chicago, Ill.

Saenger, A. (1919). Ein Fall von dauernder zerebraler Erblindung nach Hinterhauptsverletzung. Neurologisches Centralblatt, 38, 210-211.

Schilder, P., Pasik, T., and Pasik, P. (1971). Extrageniculostriate vision in the monkey. II. Demonstration of brightness discrimination. Brain Research, 32, 383-398.

Scoville, W. B., and Milner, B. (1957). Loss of recent memory after bilateral hippocampal lesions. Journal of Neurology, Neurosurgery, and Psychiatry, 20, 11-21.

Segarra, J. M. (1970). Cerebral vascular disease and behavior. I. Archives of Neurology, 22, 408-418.

Sweet, W. H., Talland, G. A., and Ervin, F. R. (1959). Loss of recent memory following section of fornix. Transactions of the American Neurological Association, 84, 76-82.

Symonds, C., and Mackenzie, I. (1957). Bilateral loss of vision from cerebral infarction. Brain, 80, 415-455.

Victor, M., Angevine, J. B., Jr, Mancall, E. L., and Fisher, C. M. (1961). Memory loss with lesions of hippocampal formation. Archives of Neurology, 5, 244-263.

Whitty, C. W. M. (1962). The neurological basis of memory. In Modern Trends in Neurology, pp. 314-335, especially p. 321, vol. 3. Edited by D. Williams. Butterworths: London. 